\title{
Implementation of a ZVS Three-Level Converter with Series-Connected Transformers
}

\author{
Bor-Ren $\operatorname{Lin}^{\dagger}$ \\ ${ }^{\dagger}$ Dept. of Electrical Eng., National Yunlin University of Science and Technology, Yunlin, Taiwan
}

\begin{abstract}
This paper studies a soft switching DC/DC converter to achieve zero voltage switching (ZVS) for all switches under a wide range of load condition and input voltage. Two three-level PWM circuits with the same power switches are adopted to reduce the voltage stress of MOSFETs at $V_{i n} / 2$ and achieve load current sharing. Thus, the current stress and power rating of power semiconductors at the secondary side are reduced. The series-connected transformers are adopted in each three-level circuit. Each transformer can be operated as an inductor to smooth the output current or a transformer to achieve the electric isolation and power transfer from the input side to the output side. Therefore, no output inductor is needed at the secondary side. Two center-tapped rectifiers connected in parallel are used at the secondary side to achieve load current sharing. Due to the resonant behavior by the resonant inductance and resonant capacitance at the transition interval, all switches are turned on at ZVS. Experiments based on a $1 \mathrm{~kW}$ prototype are provided to verify the performance of proposed converter.
\end{abstract}

Key words: DC/DC converter, Soft Switching

\section{INTRODUCTION}

Recently, high efficiency DC/DC converters have been widely used and developed for the cloud server power units and telecommunication applications. For the medium/high power applications, three-phase power factor correctors (PFC) are generally used in the front stage of the high efficiency power converters to supply a constant DC bus voltage for the rear stage $\mathrm{DC} / \mathrm{DC}$ converter. Usually, the $\mathrm{DC}$ bus voltage of a three-phase PFC is greater than $500 \mathrm{~V}-800 \mathrm{~V}$. Thus, MOSFETs with $500 \mathrm{~V}$ or $600 \mathrm{~V}$ voltage stress cannot be adopted in the second stage such as half-bridge or full-bridge circuit topology. High voltage IGBT can be used in the rear DC/DC converters. But the low switching frequency is the main drawback of IGBT for high power density applications. Although MOSFETs with $900 \mathrm{~V}$ voltage stress can be adopted in the rear DC/DC converters to overcome this problem, the main drawbacks of the high voltage MOSFETs are high cost and large turn-on resistance which will reduce the circuit efficiency. Three-level or multi-level converters/inverters [1]-[4] have been proposed to use low voltage stress of power

Manuscript received Sep. 21, 2012; revised Dec. 5, 2012

Recommended for publication by Associate Editor Sanjeet K. Dwivedi.

${ }^{\dagger}$ Corresponding Author: linbr@yuntech.edu.tw

Tel: +886-5-5516128, Fax: +886-5-5312065,

Dept. of Electrical Eng., National Yunlin University of Science and

Technology, Taiwan switches for high voltage applications. These topologies are based on the neutral point diode clamp, flying clamp or series full-bridge topology to reduce the voltage stress of each power switches at one-half of DC bus voltage. Therefore MOSFETs with $600 \mathrm{~V}$ voltage stress can be used in the rear DC/DC converter for high input voltage applications. Soft switching techniques [5]-[12] such as active clamp techniques, asymmetric half-bridge converters, series resonant techniques and phase-shift pulse-width modulation (PWM) have been proposed in order to meet the demand of modern switching converters with high efficiency, small volume and light weight. Thus, power switches can be turned off at zero current switching (ZCS) or turned on at zero voltage switching (ZVS). However, these soft switching topologies are mainly based on the two-level PWM scheme such that they cannot be used for high voltage applications. Three-level soft switching DC/DC converters [13]-[16] have been proposed to have the features of low voltage stress of power semiconductors and high circuit efficiency. In these techniques, the leakage inductance of the transformer (or external inductance) and the output capacitance of power switches are resonant at the transition interval. The drain-to-source voltage of MOSFETs can be decreased to zero voltage before the MOSFETs are turned on. In order to reduce the output inductance variation due to the different load condition, the output filter inductance is deleted and two 
series transformers [17], [18] are used in the primary side to have the almost constant magnetizing inductance.

This paper presents a soft switching DC/DC converter with two three-level DC/DC circuits with the same power switches. The main features of the proposed converter are low switching losses, ZVS turn-on and low voltage stress on MOSFETs. Two three-level PWM circuits with the same power switches are presented in order to decrease the switch count, achieve the load current sharing, reduce the current stress of the transformer windings, rectifier diodes and output filter inductors and clamp the voltage stress of active switches at $V_{\text {in }} / 2$. Two center-tapped rectifiers are adopted to reduce the current rating of passive components at the secondary side. For each three-level PWM circuit, the series-connected two transformers are used to smooth load current. One transformer works as a forward-type transformer to transfer the input power to output load, and the other transformer works as an inductor to smooth the load current. Thus no output inductor is needed at the secondary side. Based on the resonant behavior by the output capacitance of MOSFETs and the resonant inductance at the transition interval, all MOSFETs can be turned on at ZVS with a wide range of load current. Experiments with a $1 \mathrm{~kW}$ prototype are provided to verify the theoretical analysis and demonstrate the effectiveness of the proposed converter.

\section{CIRCUIT CONFIGURATION}

The circuit configuration of the proposed converter is shown in Fig. 1. Input capacitances $C_{i n 1}$ and $C_{i n 2}$ are equal and large enough to share the input voltage $v_{\text {Cin } 1}=v_{\text {Cin } 2}=V_{i n} / 2$. Switches $S_{1}-S_{4}$ are MOSFETs with the voltage stresses $V_{i n} / 2$. $C_{r l}-C_{r 4}$ are output capacitances of $S_{l}-S_{4}$, respectively. $D_{a}$ and $D_{b}$ are the clamped diodes. $C_{f}$ is the flying capacitor and its voltage is equal to $V_{i n} / 2 . C_{1}$ and $C_{2}$ are the DC blocking capacitances with the average voltages $V_{C l}=V_{C 2}=V_{i n} / 2 . L_{r 1}$ and $L_{r 2}$ are the resonant inductances. $L_{m l}-L_{m 4}$ are the magnetizing inductances of the transformers $T_{1}-T_{4}$, respectively. $D_{1}-D_{4}$ are the rectifier diodes. $R_{o}$ and $C_{o}$ denote the load resistance and output capacitance. Phase-shift PWM scheme is used to regulate the output voltage. $S_{I}$ and $S_{4}$ are the leading switches and $S_{2}$ and $S_{3}$ are the lagging switches. Two three-level PWM circuits with the same MOSFETs are adopted in the proposed converter. The components of the circuit 1 include $C_{i n l}, C_{i n 2}$, $D_{a}, D_{b}, C_{f}, S_{l}-S_{4}, C_{r l}-C_{r 4}, C_{l}, L_{r l}, T_{l}, T_{2}, D_{l}$ and $D_{2}$. The circuit 2 includes the components of $C_{i n 1}, C_{i n 2}, D_{a}, D_{b}, C_{f}$, $S_{1}-S_{4}, C_{r I}-C_{r 4}, C_{2}, L_{r 2}, T_{3}, T_{4}, D_{3}$ and $D_{4}$. Circuit 1 and circuit 2 are operated by the phase shift of one-half of switching cycle. Three voltage levels $V_{i n}, V_{i n} / 2$ and 0 are generated on $v_{a b}$ and $v_{b c}$. Since the average voltages $V_{C l}=V_{C 2}=V_{i n} / 2$, three voltage levels $V_{i n} / 2,0$ and $-V_{i n} / 2$ are generated on $v_{p 1}$ and $v_{p 2}$. However, the voltages $v_{p 1}=-v_{p 2}$. Two series transformers are used in each circuit. Each transformer can be operated as

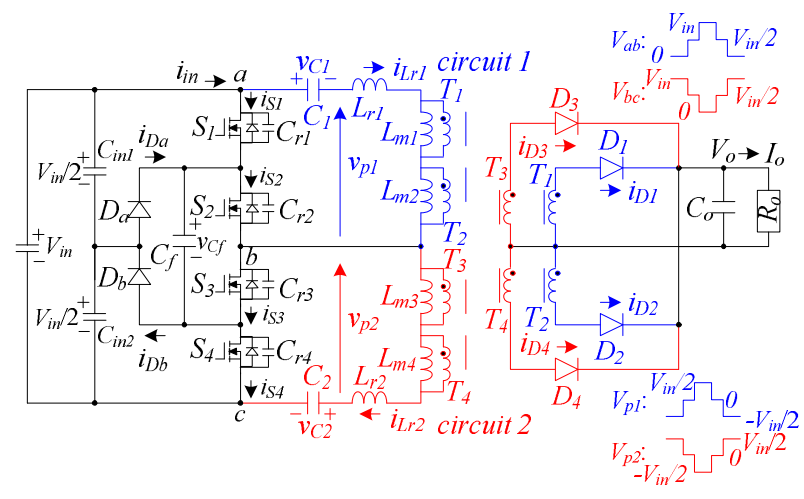

Fig. 1. Proposed new ZVS DC/DC converter.

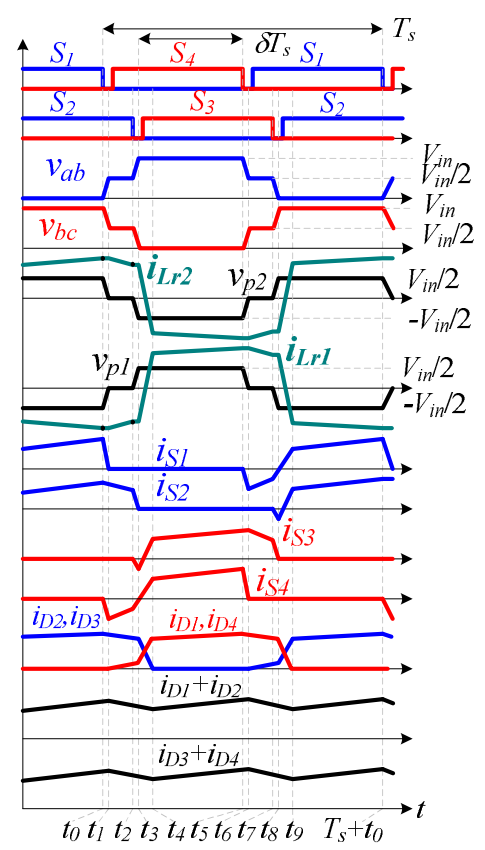

Fig. 2. Key waveforms of the proposed converter.

transformers to achieve electric isolation and power transfer or operated as inductors to smooth output current. Thus, no inductor is needed in the output side.

\section{OPERATION PRINCIPLE}

The theoretical PWM waveforms of the proposed converter in a switching cycle are given in Fig. 2. Before the discussion the operation principle, some assumptions are made to simplify the system analysis of the proposed converter. (1) Power semiconductors $S_{1}-S_{4}, D_{1}-D_{4}$ and $D_{a}-D_{b}$ are ideal. (2) Four transformers are identical $\left(L_{m l}=L_{m 2}=L_{m 3}=L_{m 4}=L_{m}\right)$. (3) Resonant inductances are identical $L_{r 1}=L_{r 2}=L_{r}<<L_{m}$. (4) $C_{i n 1}=C_{i n 2}$ are large enough to be considered as two voltage sources $V_{\text {Cin } 1}=V_{\text {Cin } 2}=V_{i n} / 2$. (5) Switch output capacitances $C_{r l}=C_{r 2}=C_{r 3}=C_{r 4}=C_{r}$. (6) $C_{1}, C_{2}$ and $C_{f}$ are large enough to be treated as three constant voltages $V_{C l}=V_{C 2}=V_{C f}=V_{i n} / 2$. (7) The output voltage is constant. Based on the on/off states of $S_{1}-S_{4}, D_{a}-D_{b}$ and $D_{1}-D_{4}$, 
there are ten operation modes in the proposed converter during a switching period. The duty cycle of each switch is equal to 0.5 . The PWM signals of $S_{2}$ and $S_{3}$ are phase-shifted with respective to the PWM signals of $S_{1}$ and $S_{4}$. Fig. 3 shows the equivalent circuits of ten operation modes in a switching period. Prior to time $t_{0}, S_{1}, S_{2}, D_{2}$ and $D_{3}$ are conducting.

Mode $1\left[\boldsymbol{t}_{0} \leq \boldsymbol{t}<\boldsymbol{t}_{1}\right]$ : At $t_{0}, S_{1}$ is turned off. Since $i_{L r l}\left(t_{0}\right)<0$ and $i_{L r 2}\left(t_{0}\right)>0, C_{r l}$ is charged linearly from zero voltage and $C_{r 4}$ is discharged linearly from $V_{i n} / 2$ via the flying capacitor $C_{f}$. The rising slope of the drain-to-source voltage of $S_{I}$ (or $v_{C r l}$ ) is limited by $C_{r l}$ and $C_{r 4}$. Thus, $S_{l}$ is turned off at ZVS. If the energy stored in $L_{m l}$ and $L_{m 4}$ is greater than the energy stored in $C_{r 1}$ and $C_{r 4}$, then $C_{r 4}$ can be discharged to zero voltage. Thus, the ZVS turn-on condition of $S_{4}$ is given as:

$$
\left(L_{r}+L_{m}\right)\left[i_{L r 1}^{2}\left(t_{0}\right)+i_{L r 2}^{2}\left(t_{0}\right)\right] \geq \frac{C_{r} V_{i n}^{2}}{2}
$$

At $t_{1}, v_{C r l}=V_{i n} / 2$ and $v_{C r 4}=0$. The time interval of mode 1 is expressed as:

$$
\Delta t_{01}=t_{1}-t_{0}=\frac{C_{r} V_{i n}}{i_{L r 2}\left(t_{0}\right)-i_{L r 1}\left(t_{0}\right)}
$$

The time delay $t_{d}$ between $S_{I}$ and $S_{4}$ must be greater than $\Delta t_{01}$ in order to achieve ZVS turn-on of $S_{4}$.

Mode $2\left[t_{1} \leq t<t_{2}\right]$ : At $t_{1}, v_{C r l}=V_{i n} / 2$ such that $D_{a}$ is conducting and $v_{C r 4}=0$. Since $i_{L r l}\left(t_{1}\right)<0$ and $i_{L r 2}\left(t_{1}\right)>0$, the switch current $i_{S 4}$ is negative and the anti-parallel diode of $S_{4}$ is conducting. Thus, $S_{4}$ can be turned on at this moment to achieve ZVS. In this mode, $v_{a b}=v_{b c}=V_{i n} / 2$ and $v_{p 1} \approx v_{L m 1}+v_{L m 2}=v_{L m 3}+v_{L m 4}=0$. Thus, $D_{I}-D_{4}$ are all conducting. The magnetizing voltages of $T_{1}-T_{4}$ are $v_{L m 1}=v_{L m 3}=n V_{o}$ and $v_{L m 2}=v_{L m 4}=-n V_{o}$. Diode currents $i_{D 1}$ and $i_{D 4}$ increase, and $i_{D 2}$ and $i_{D 3}$ decrease. If the voltage drop on diode $D_{a}$ and switch $S_{2}$ are considered, the primary side currents $i_{L r 1}$ and $i_{L r 2}$ can be expressed as:

$$
\begin{aligned}
& i_{L r 1}(t)=i_{L r 1}\left(t_{1}\right)+\frac{V_{S 2, \text { drop }}+V_{D a, d r o p}}{L_{r}}\left(t-t_{1}\right) \\
& i_{L r 2}(t)=i_{L r 2}\left(t_{1}\right)-\frac{V_{S 2, \text { drop }}+V_{D a, d r o p}}{L_{r}}\left(t-t_{1}\right)
\end{aligned}
$$

where $V_{S 2 \text {,drop }}$ and $V_{D a, \text { drop }}$ are the voltage drop on switch $S_{2}$ and diode $D_{a}$, respectively. The slopes of the diode currents are given as:

$$
\begin{aligned}
& \frac{d i_{D 1}(t)}{d t}=\frac{d i_{D 4}(t)}{d t}=\frac{n\left(V_{S 2, \text { drop }}+V_{D a, \text { drop }}\right)}{2 L_{r}} \\
& \frac{d i_{D 2}(t)}{d t}=\frac{d i_{D 3}(t)}{d t}=-\frac{n\left(V_{S 2, \text { drop }}+V_{D a, \text { drop }}\right)}{2 L_{r}}
\end{aligned}
$$

where $n=n_{p} / n_{s}$ is the turns ratio of $T_{1}-T_{4}$. If the voltage drop on $S_{2}$ and diode $D_{a}$ can be neglected, then the primary currents $i_{L r 1}$ and $i_{L r 2}$ and diode currents $i_{D I-} i_{D 4}$ are unchanged in this mode. At time $t_{2}, S_{2}$ is turned off.

Mode $3\left[\boldsymbol{t}_{2} \leq \boldsymbol{t}<\boldsymbol{t}_{3}\right]: S_{2}$ is turned off at $t_{2}$. Since $i_{L r I}\left(t_{2}\right)<0$ and $i_{L r 2}\left(t_{2}\right)>0, C_{r 2}$ is charged linearly from zero voltage and $C_{r 3}$ is discharged linearly from $V_{i n} / 2$ via the flying capacitor $C_{f}$. The rising slope of $v_{C r 2}$ is limited by $C_{r 2}$ and $C_{r 3}$. Thus, $S_{2}$ is turned off at ZVS. Since $D_{I}-D_{4}$ are still conducting in this mode, the magnetizing voltages $v_{L m 1}=v_{L m 3}=n V_{o}$ and $v_{L m 2}=v_{L m 4}=-n V_{o}$. If the energy stored in $L_{r 1}$ and $L_{r 2}$ is greater than the energy stored in $C_{r 2}$ and $C_{r 3}$, then $C_{r 3}$ can be discharged to zero voltage. Thus, the ZVS turn-on condition of $S_{3}$ is given as:

$$
L_{r}\left[i_{L r 1}^{2}\left(t_{2}\right)+i_{L r 2}^{2}\left(t_{2}\right)\right] \geq C_{r} V_{i n}^{2} / 2
$$

At time $t_{3}, v_{C r 3}=0$. The time interval in mode 3 is expressed as:

$$
\Delta t_{23}=t_{3}-t_{2}=\frac{C_{r} V_{i n}}{i_{L r 2}\left(t_{2}\right)-i_{L r 1}\left(t_{2}\right)}
$$

The time delay $t_{d}$ between $S_{2}$ and $S_{3}$ must be greater than $\Delta t_{23}$ in order to achieve ZVS turn-on of $S_{3}$.

Mode $4\left[\boldsymbol{t}_{3} \leq \boldsymbol{t}<\boldsymbol{t}_{4}\right]$ : At $t_{3}, v_{C r 3}=0$. Since $i_{S 3}\left(t_{3}\right)=i_{L r 1}\left(t_{3}\right)-i_{L r 2}\left(t_{3}\right)<0$, the anti-parallel diode of $S_{3}$ is conducting. Thus, $S_{3}$ can be turned on at this moment to achieve ZVS. In this mode, the voltages $v_{a b}=V_{i n}, v_{b c}=0, v_{p l}=V_{i n} / 2$ and $v_{p 2}=-V_{i n} / 2$. Since $D_{l}-D_{4}$ are still conducting, the primary side voltages $v_{L m I}+v_{L m 2}=0$ and $v_{L m 3}+v_{L m 4}=0$. Thus, the inductor voltages $v_{L r 1}=V_{i n} / 2$ and $v_{L r 2}=-V_{i n} / 2$. The primary side currents are illustrated as:

$$
\begin{gathered}
i_{L r 1}(t)=i_{L r 1}\left(t_{3}\right)+\frac{V_{\text {in }}}{2 L_{r}}\left(t-t_{3}\right) \\
i_{L r 2}(t)=i_{L r 2}\left(t_{3}\right)-\frac{V_{\text {in }}}{2 L_{r}}\left(t-t_{3}\right)
\end{gathered}
$$

The inductor current $i_{L r 1}$ increases and $i_{L r 2}$ decreases in this mode. The slopes of the diode currents are given as:

$$
\begin{gathered}
\frac{d i_{D 1}(t)}{d t}=\frac{d i_{D 4}(t)}{d t}=\frac{n V_{i n}}{4 L_{r}} \\
\frac{d i_{D 2}(t)}{d t}=\frac{d i_{D 3}(t)}{d t}=-\frac{n V_{i n}}{4 L_{r}}
\end{gathered}
$$

At time $t_{4}$, diode currents $i_{D 2}$ and $i_{D 3}$ are decreased to zero. In this mode, no power is transferred from input voltage source $V_{\text {in }}$ to output load $R_{o}$. Thus, the duty loss in mode 4 is expressed as:

$$
\delta_{\text {loss }, 4}=\frac{\Delta t_{34}}{T_{s}} \approx \frac{2 L_{r} I_{o} f_{s}}{n V_{\text {in }}}
$$

where $T_{s}$ and $f_{s}$ are the switching period and switching frequency, respectively.

Mode 5 [ $\left.\boldsymbol{t}_{4} \leq \boldsymbol{t}<\boldsymbol{t}_{\mathbf{5}}\right]$ : At $t_{4}, i_{D 2}=i_{D 3}=0 . T_{1}$ and $T_{4}$ are working as the forward type transformers and $T_{2}$ and $T_{3}$ are working as the inductors to smooth the load current. The voltages $v_{p 1}=V_{i n} / 2$ and $v_{p 2}=-V_{i n} / 2$ in mode 5 . Thus, the primary current $i_{L r l}$ increases linearly with the applied $V_{i n} / 2$ and $i_{L r 2}$ decreases linearly with the applied voltage $-V_{i n} / 2$ in this mode.

$$
\begin{aligned}
& i_{L r 1}(t) \approx i_{L r 1}\left(t_{4}\right)+\frac{V_{i n} / 2-n V_{o}}{L_{r}+L_{m}}\left(t-t_{4}\right) \\
& i_{L r 2}(t) \approx i_{L r 2}\left(t_{4}\right)-\frac{V_{i n} / 2-n V_{o}}{L_{r}+L_{m}}\left(t-t_{4}\right)
\end{aligned}
$$

Power is delivered from input voltage source $V_{\text {in }}$ to output load $R_{o}$ in this mode.

Mode $6\left[\boldsymbol{t}_{5} \leq \boldsymbol{t}<\boldsymbol{t}_{6}\right]$ : At $t_{5}, S_{4}$ is turned off. Since $i_{L r I}\left(t_{5}\right)>0$ and 
$i_{L r 2}\left(t_{5}\right)<0, \quad C_{r l}$ and $C_{r 4}$ are discharged and charged, respectively, via capacitor $C_{f}$. The rising slope of the drain-to-source voltage of $S_{4}$ is limited by $C_{r l}$ and $C_{r 4}$. Therefore, $S_{4}$ is turned off at ZVS. If the energy stored in $L_{m 2}$ and $L_{m 3}$ is greater than the energy stored in $C_{r l}$ and $C_{r 4}$, then $C_{r l}$ can be discharged to zero voltage. Thus, the ZVS turn-on condition of $S_{l}$ is given as:

$$
\left(L_{r}+L_{m}\right)\left[i_{L r 1}^{2}\left(t_{5}\right)+i_{L r 2}^{2}\left(t_{5}\right)\right] \geq C_{r} V_{\text {in }}^{2} / 2
$$

At time $t_{6}, v_{C r I}=0$ and $v_{C r 4}=V_{i n} / 2$. The time interval in mode 6 is given as:

$$
\Delta t_{56}=t_{6}-t_{5}=\frac{C_{r} V_{i n}}{i_{L r 1}\left(t_{5}\right)-i_{L r 2}\left(t_{5}\right)}
$$

The time delay $t_{d}$ between $S_{l}$ and $S_{4}$ should be greater than $\Delta t_{56}$ in order to achieve ZVS turn-on of $S_{1}$.

Mode $7 \quad\left[\boldsymbol{t}_{6} \leq \boldsymbol{t}<\boldsymbol{t}_{7}\right]$ : At time $t_{6}, v_{C r 4}=V_{\text {in }} / 2$ such that $D_{b}$ is conducting and $v_{C r 1}=0$. Since $i_{L r 1}\left(t_{6}\right)>0$ and $i_{L r 2}\left(t_{6}\right)<0$, the switch current $i_{S I}$ is negative and the anti-parallel diode of $S_{I}$ is conducting. Thus, $S_{l}$ can be turned on at this moment to achieve ZVS. In this mode, the voltages $v_{a b}=v_{b c}=V_{i n} / 2$ and $v_{p 1} \approx v_{L m 1}+v_{L m 2}=v_{L m 3}+v_{L m 4}=0$. Thus, $D_{I}-D_{4}$ are conducting. The primary side currents are expressed as:

$$
\begin{aligned}
& i_{L r 1}(t)=i_{L r 1}\left(t_{6}\right)-\frac{V_{S 3, \text { drop }}+V_{D b, \text { drop }}}{L_{r}}\left(t-t_{6}\right) \\
& i_{L r 2}(t)=i_{L r 2}\left(t_{6}\right)+\frac{V_{S 3, \text { drop }}+V_{D b, \text { drop }}}{L_{r}}\left(t-t_{6}\right)
\end{aligned}
$$

where $V_{S 3, \text { drop }}$ and $V_{D b \text {,drop }}$ are the voltage drop on switch $S_{3}$ and diode $D_{b}$, respectively. The slopes of the diode currents are given as:

$$
\begin{aligned}
& \frac{d i_{D 1}(t)}{d t}=\frac{d i_{D 4}(t)}{d t}=-\frac{n\left(V_{S 3, \text { drop }}+V_{D b, d r o p}\right)}{2 L_{r}} \\
& \frac{d i_{D 2}(t)}{d t}=\frac{d i_{D 3}(t)}{d t}=\frac{n\left(V_{S 3, d r o p}+V_{D b, \text { drop }}\right)}{2 L_{r}}
\end{aligned}
$$

Diode currents $i_{D 1}$ and $i_{D 4}$ decrease and $i_{D 2}$ and $i_{D 3}$ increase. At time $t_{7}, S_{3}$ is turned off.

Mode $\boldsymbol{8}\left[\boldsymbol{t}_{7} \leq \boldsymbol{t}<\boldsymbol{t}_{\boldsymbol{8}}\right]$ : At $t_{7}, S_{3}$ is turned off. $C_{r 2}$ and $C_{r 3}$ are discharged and charged, respectively. Since the rising slope of $v_{C r 3}$ is limited by $C_{r 2}$ and $C_{r 3}, S_{3}$ is turned off at ZVS. $D_{1}-D_{4}$ are all conducting in this mode, the magnetizing voltages $v_{L m 1}=v_{L m 3}=n V_{o}$ and $v_{L m 2}=v_{L m 4}=-n V_{o}$. If the energy stored in $L_{r 1}$ and $L_{r 2}$ is greater than the energy stored in $C_{r 2}$ and $C_{r 3}$, then $C_{r 2}$ can be discharged to zero voltage. Thus, the ZVS turn-on condition of $S_{2}$ is given as:

$$
L_{r}\left[i_{L r 1}^{2}\left(t_{7}\right)+i_{L r 2}^{2}\left(t_{7}\right)\right] \geq C_{r} V_{i n}^{2} / 2
$$

At time $t_{8}, v_{C r 2}=0$ and $v_{C r 3}=V_{i n} / 2$. The time interval of mode 8 is expressed as:

$$
\Delta t_{78}=t_{8}-t_{7}=\frac{C_{r} V_{i n}}{i_{L r 1}\left(t_{7}\right)-i_{L r 2}\left(t_{7}\right)}
$$

The time delay $t_{d}$ between $S_{2}$ and $S_{3}$ should be greater than $\Delta t_{78}$ in order to achieve ZVS turn-on of $S_{2}$.

Mode $9\left[\boldsymbol{t}_{\boldsymbol{8}} \leq \boldsymbol{t}<\boldsymbol{t}_{\boldsymbol{g}}\right]$ : At $t_{8}, v_{C r 2}=0$. Since $i_{S 2}\left(t_{8}\right)=i_{L r 2}\left(t_{8}\right)-i_{L r 1}\left(t_{8}\right)<0$, the anti-parallel diode of $S_{2}$ is conducting. Thus, $S_{2}$ can be turned on at this moment to achieve ZVS. In mode 9, the voltages $v_{a b}=0, v_{b c}=V_{i n}, v_{p l}=-V_{i n} / 2$ and $v_{p 2}=V_{i n} / 2$. Since $D_{l}-D_{4}$ are still conducting and $v_{L m 1}+v_{L m 2}=v_{L m 3}+v_{L m 4}=0$, the inductor voltages $v_{L r I}=-V_{i n} / 2$ and $v_{L r 2}=V_{i n} / 2$. The primary side currents and the slopes of the diode currents are given as:

$$
\begin{aligned}
& i_{L r 1}(t)=i_{L r 1}\left(t_{8}\right)-\frac{V_{i n}}{2 L_{r}}\left(t-t_{8}\right) \\
& i_{L r 2}(t)=i_{L r 2}\left(t_{8}\right)+\frac{V_{\text {in }}}{2 L_{r}}\left(t-t_{8}\right) \\
& \frac{d i_{D 1}(t)}{d t}=\frac{d i_{D 4}(t)}{d t}=-\frac{n V_{i n}}{4 L_{r}} \\
& \frac{d i_{D 2}(t)}{d t}=\frac{d i_{D 3}(t)}{d t}=\frac{n V_{i n}}{4 L_{r}}
\end{aligned}
$$

At $t_{9}$, the diode currents $i_{D I}$ and $i_{D 4}$ are decreased to zero. The duty loss in mode 9 is expressed as:

$$
\delta_{\text {loss }, 9}=\frac{\Delta t_{89}}{T_{s}} \approx \frac{2 L_{r} I_{o} f_{s}}{n V_{\text {in }}}=\delta_{\text {loss }, 4}
$$

Mode $10\left[\boldsymbol{t}_{\boldsymbol{g}} \leq \boldsymbol{t}<\boldsymbol{t}_{\boldsymbol{0}}+\boldsymbol{T}_{\boldsymbol{s}}\right]$ : At $t_{9}, i_{D I}=i_{D 4}=0 . T_{2}$ and $T_{3}$ are working as the forward type transformers and $T_{1}$ and $T_{4}$ are working as the inductors to smooth the load current. The voltages $v_{p 1}=-V_{i n} / 2$ and $v_{p 2}=V_{i n} / 2$ in mode 10 . Thus, the primary current $i_{L r l}$ decreases linearly with the applied $-V_{i n} / 2$ and $i_{L r 2}$ increases linearly with the applied voltage $V_{i n} / 2$ in this mode.

$$
\begin{gathered}
i_{L r 1}(t)=i_{L r 1}\left(t_{9}\right)-\frac{V_{i n} / 2-n V_{o}}{L_{r}+L_{m}}\left(t-t_{9}\right) \\
i_{L r 2}(t)=i_{L r 2}\left(t_{9}\right)+\frac{V_{i n} / 2-n V_{o}}{L_{r}+L_{m}}\left(t-t_{9}\right)
\end{gathered}
$$

This mode ends at $t_{0}+T_{s}$ when $S_{I}$ is turned off. The circuit operations of the proposed converter in a switching period are completed.

\section{DESIGN CONSIDERATIONS}

We neglect the effects of circuit in modes 1, 3, 6 and 8 . Only modes 2, 4, 5, 7, 9 and 10 are discussed in this section. The average flying capacitor voltage $V_{C f}$ is equal to $V_{i n} / 2$ in modes 2 and 7. Based on the volt-second balance on $L_{r l}, L_{m l}$ and $L_{m 2}$, the average capacitor voltage $V_{C I}$ is also equal to $V_{i n} / 2$. Similarly, the average capacitor voltage $V_{C 2}$ is obtained as $V_{i n} / 2$. Based on the volt-second balance on $L_{m l}$, the output voltage can be obtained as:

$$
V_{o}=\frac{V_{i n}}{2 n}\left(\delta-\delta_{\text {loss }, 4}\right)-V_{D}=\frac{V_{i n}}{2 n}\left(\delta-\frac{2 L_{r} I_{o} f_{s}}{n V_{\text {in }}}\right)-V_{D}
$$

where $V_{D}$ is the voltage drop on diode $D_{1}-D_{4}$, and $\delta$ is the duty ratio of the proposed converter when $S_{1}$ and $S_{2}$ are both in the on-state. The output voltage $V_{o}$ is related to duty cycle $\delta$, input voltage $V_{i n}$, switching frequency $f_{s}$, resonant inductance $L_{r}$, turns ratio $n$ and load current $I_{o}$. In steady state, the average output diode currents $I_{D I}=I_{D 2}=I_{D 3}=I_{D 4}=I_{o} / 4$. If the 
ripple magnetizing current $\Delta i_{L m l}$ in mode 10 is less than the diode current reflected to primary side $i_{D 2} / n$, then the ripple inductor current $\Delta i_{L r l}$ in mode 10 can be expressed as:

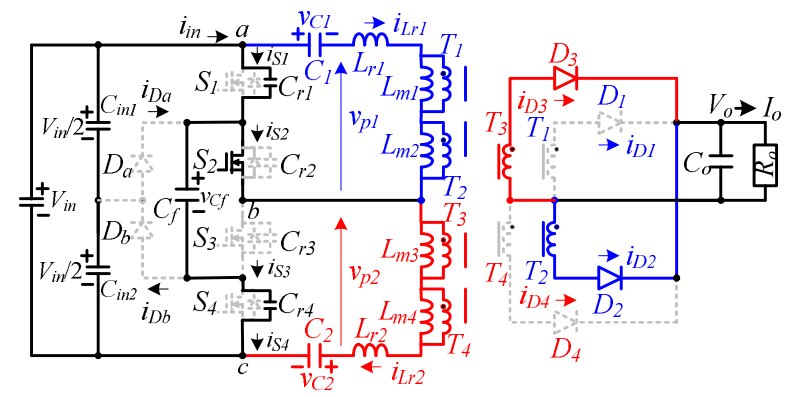

(a)

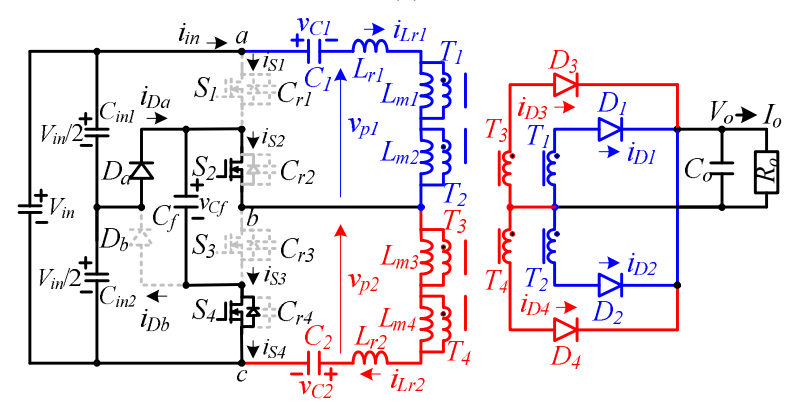

(b)

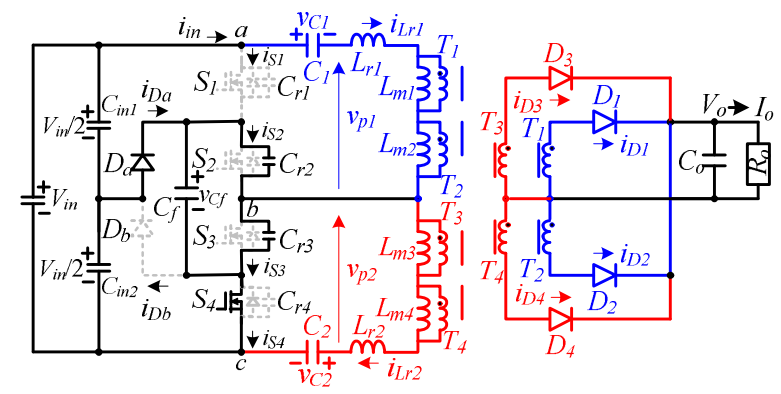

(c)

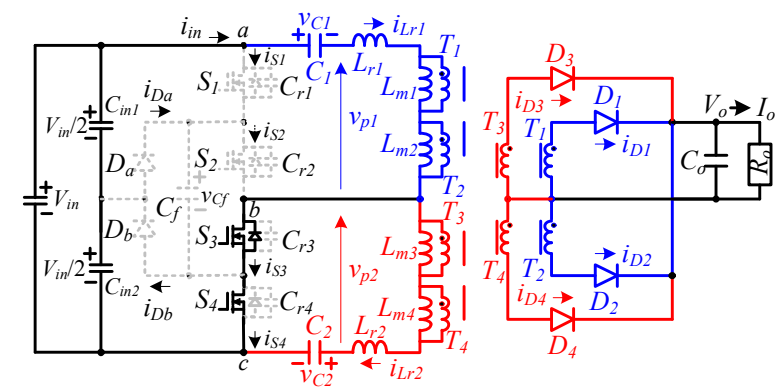

(d)

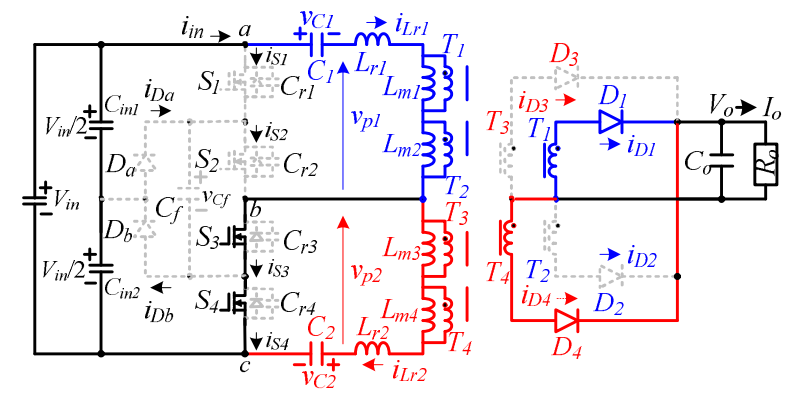

(e)

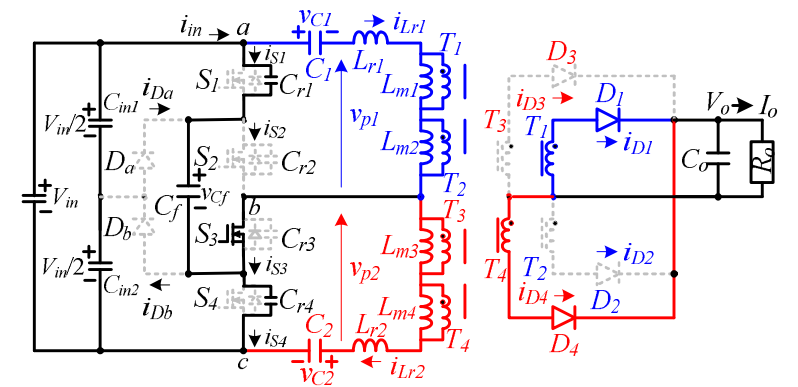

(f)

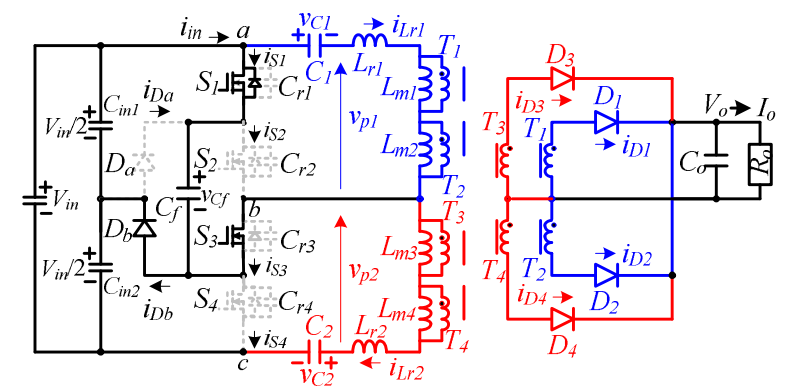

(g)

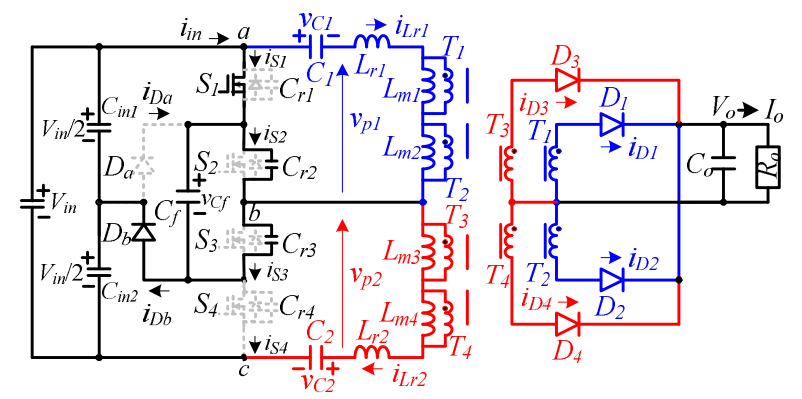

(h)

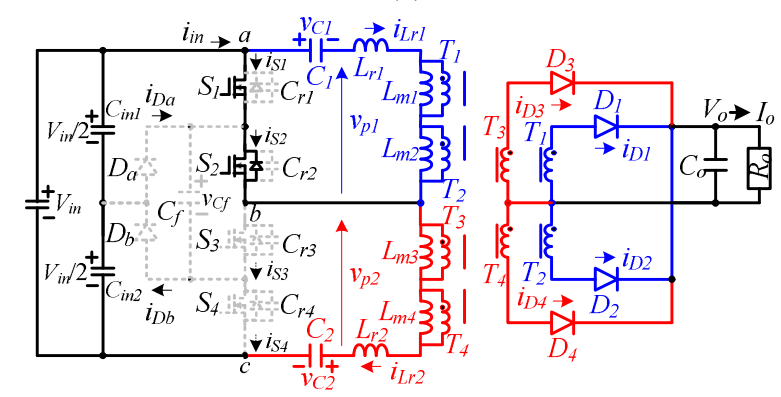

(i)

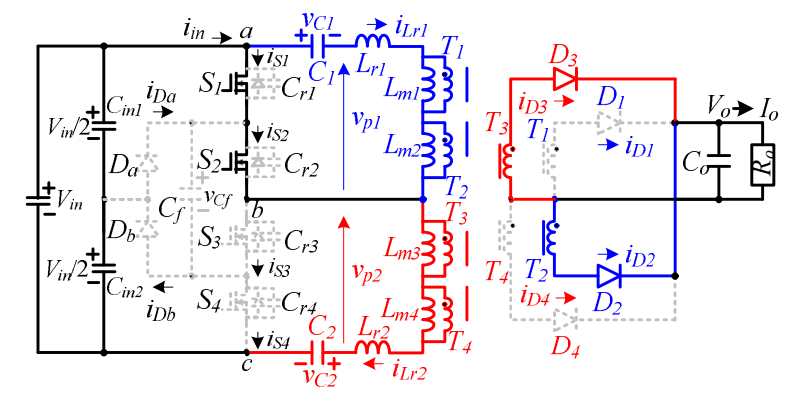

(j)

Fig. 3. Operation modes of the proposed converter during one switching cycle (a) mode 1 (b) mode 2 (c) mode 3 (d) mode 4 (e) mode 5 (f) mode 6 (g) mode 7 (h) mode 8 (i) mode 9 (j) mode 10. 


$$
\Delta i_{L r 1} \approx \frac{V_{\text {in }}-2 n\left(V_{o}+V_{D}\right)}{2 L_{m}}\left(\delta-\frac{2 L_{r} I_{o} f_{s}}{n V_{\text {in }}}\right) T_{s} \approx r I_{o}
$$

where $r$ is the ripple current ratio of load current. From (31) and (32), the magnetizing inductance $L_{m}$ of $T_{1}-T_{4}$ is given as:

$$
L_{m} \approx \frac{2 n^{2}\left(V_{o}+V_{D}\right)\left(1-\delta+\frac{2 L_{r} I_{o} f_{s}}{n V_{i n}}\right)}{r I_{o} f_{s}}
$$

The maximum diode currents are expressed as:

$$
\begin{aligned}
i_{D 1, \text { max }}=i_{D 2, \text { max }} & =i_{D 3, \max }=i_{D 4, \max } \\
& \approx \frac{I_{o}}{2}+\frac{n^{2}\left(V_{o}+V_{D}\right)}{2 L_{m} f_{s}}\left(1-\delta+\frac{2 L_{r} I_{o} f_{s}}{n V_{i n}}\right)
\end{aligned}
$$

Since the average currents on capacitances $C_{1}$ and $C_{2}$ are zero, the average magnetizing currents $I_{L m l}-I_{L m 4}$ equal zero. In modes 5 and 10, we can obtain the voltage stresses of $D_{I}-D_{4}$.

$$
v_{D 1 \text {, stress }}=v_{D 2, \text { stress }}=v_{D 3, \text { stress }}=v_{D 4, \text { stress }} \approx V_{\text {in }} /(2 n)(35)
$$

The peak currents of switches $S_{1}-S_{4}$ are given as:

$$
\begin{aligned}
i_{S 2, \text { max }}=i_{S 3, \text { max }} & =i_{S 4, \text { max }}=i_{S 1, \text { max }} \\
& \approx \frac{I_{o}}{n}+\frac{n\left(V_{o}+V_{D}\right)}{L_{m} f_{s}}\left(1-\delta+\frac{2 L_{r} I_{o} f_{s}}{n V_{\text {in }}}\right)
\end{aligned}
$$

In Fig. 3, power is delivered from input source voltage to output load in modes 5 and 10. Thus, the root-mean-square (rms) currents of $S_{1}-S_{4}$ can be expressed as:

$$
i_{S 1, r m s}=i_{S 2, r m s}=i_{S 3, r m s}=i_{S 4, r m s} \approx \frac{I_{o}}{n \sqrt{2}}
$$

The voltage stresses of $S_{1}-S_{4}$ are expressed as:

$$
V_{S 1, \text { stress }}=V_{S 2, \text { stress }}=V_{S 3, \text { stress }}=V_{S 4, \text { stress }}=V_{\text {in }} / 2 \text { (38) }
$$

In mode 10 , the inductor currents $i_{L r I}\left(t_{0}\right)$ (or $\left.i_{L r l}\left(T_{s}+t_{0}\right)\right)$ and $i_{L r 2}\left(t_{0}\right)\left(\right.$ or $\left.i_{L r 2}\left(T_{s}+t_{0}\right)\right)$ are expressed as:

$$
\begin{aligned}
& i_{L r 1}\left(t_{0}\right) \approx-\frac{I_{o}}{2 n}-\frac{n\left(V_{o}+V_{D}\right)}{2 L_{m} f_{s}}\left(1-\delta+\frac{2 L_{r} I_{o} f_{s}}{n V_{i n}}\right) \\
& i_{L r 2}\left(t_{0}\right) \approx \frac{I_{o}}{2 n}+\frac{n\left(V_{o}+V_{D}\right)}{2 L_{m} f_{s}}\left(1-\delta+\frac{2 L_{r} I_{o} f_{s}}{n V_{i n}}\right)
\end{aligned}
$$

In mode 2 , the inductor currents $i_{L r 1}\left(t_{2}\right)$ and $i_{L r 2}\left(t_{2}\right)$ are given as:

$$
\begin{aligned}
& i_{L r 1}\left(t_{2}\right) \approx i_{L r 1}\left(t_{0}\right)+\frac{\left(V_{S 2, \text { drop }}+V_{D a, d r o p}\right)}{L_{r} f_{s}}(0.5-\delta)=-\frac{I_{o}}{2 n} \\
& -\frac{n\left(V_{o}+V_{D}\right)}{2 L_{m} f_{s}}\left(1-\delta+\frac{2 L_{r} I_{o} f_{s}}{n V_{\text {in }}}\right)+\frac{\left(V_{S 2, \text { drop }}+V_{D a, d r o p}\right)}{L_{r} f_{s}}(0.5-\delta) \\
& i_{L r 2}\left(t_{2}\right) \approx i_{L r 2}\left(t_{0}\right)-\frac{\left(V_{S 2, \text { drop }}+V_{D a, d r o p}\right)}{L_{r} f_{s}}(0.5-\delta)=\frac{I_{o}}{2 n} \\
& +\frac{n\left(V_{o}+V_{D}\right)}{2 L_{m} f_{s}}\left(1-\delta+\frac{2 L_{r} I_{o} f_{s}}{n V_{\text {in }}}\right)-\frac{\left(V_{S 2, \text { drop }}+V_{\text {Da,drop }}\right)}{L_{r} f_{s}}(0.5-\delta)
\end{aligned}
$$

From (1) and (16), the necessary resonant inductance $L_{r}$ for ZVS turn-on of $S_{l}$ and $S_{4}$ is given as:

$$
L_{r} \geq \frac{C_{r} V_{i n}^{2}}{2\left[i_{L r 1}^{2}\left(t_{0}\right)+i_{L r 2}^{2}\left(t_{0}\right)\right]}-L_{m}
$$

From (7) and (22), the necessary inductance $L_{r}$ to achieve ZVS turn-on of $S_{2}$ and $S_{3}$ is given as:

$$
L_{r} \geq \frac{C_{r} V_{i n}^{2}}{2\left[i_{L r 1}^{2}\left(t_{2}\right)+i_{L r 2}^{2}\left(t_{2}\right)\right]}
$$

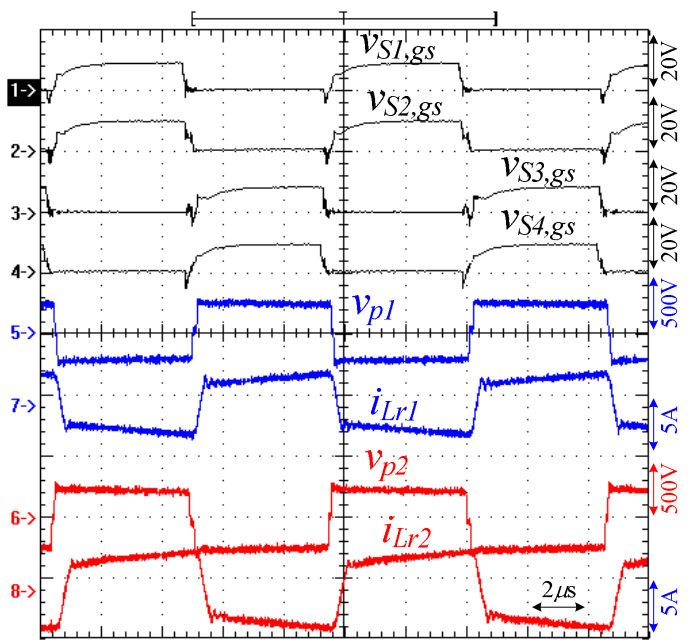

(a)

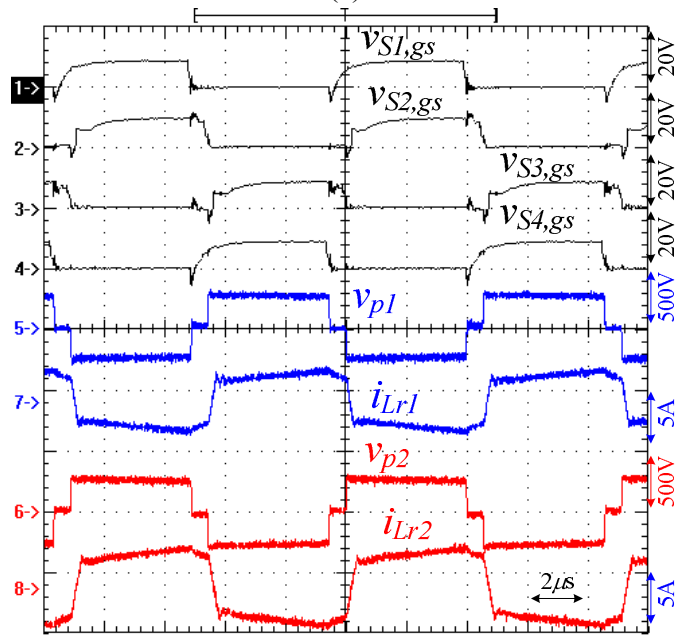

(b)

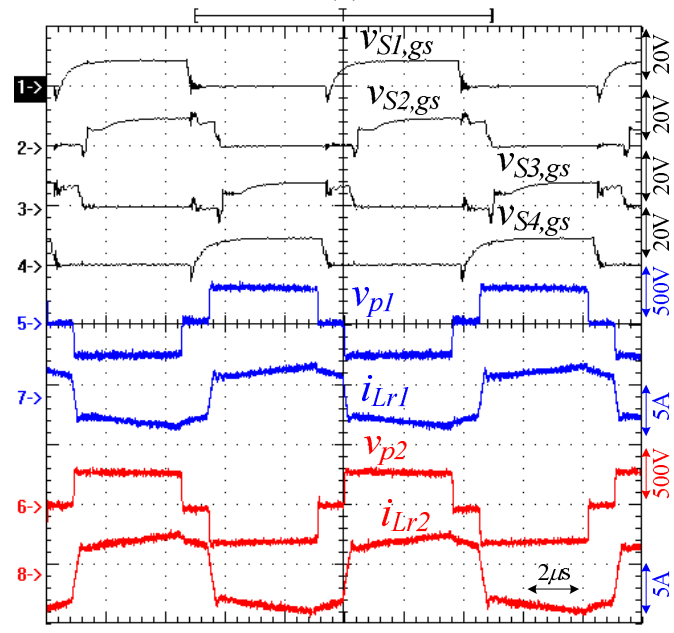

(c)

Fig. 4. Measured results of the gate voltages of $S_{I}-S_{4}$, the primary side voltages and currents at full load and (a) $V_{i n}=480 \mathrm{~V}$ (b) $V_{\text {in }}=530 \mathrm{~V}$ (c) $V_{\text {in }}=580 \mathrm{~V}$.

\section{EXPERIMENTAL RESULTS}

Experiments with a laboratory prototype are provided to verify the theoretical analysis and demonstrate the 


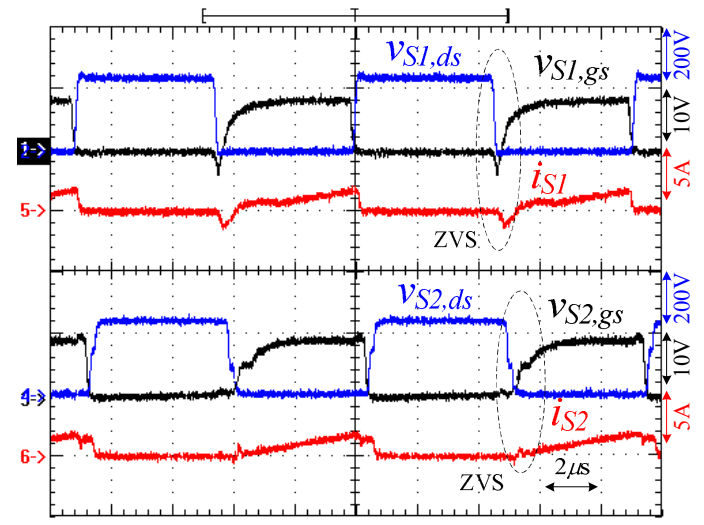

(a)

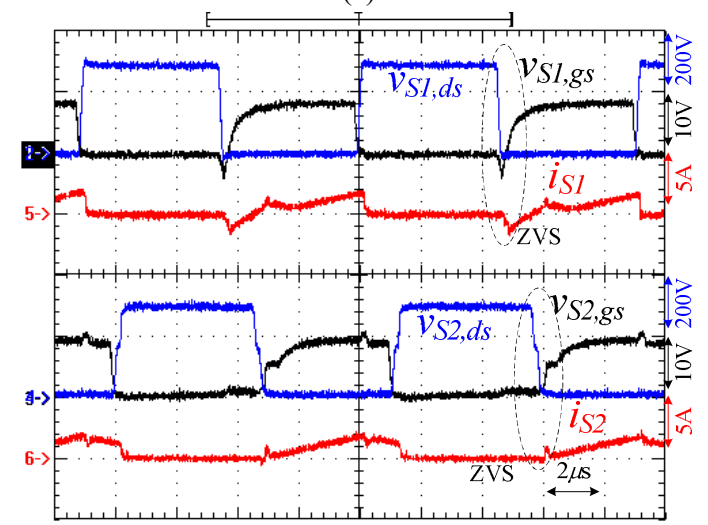

(b)

Fig. 5. Measured waveforms of the gate voltage, drain voltage and switch current of switches $S_{I}$ and $S_{2}$ at $20 \%$ load and (a) $V_{\text {in }}=480 \mathrm{~V}$ (b) $V_{\text {in }}=580 \mathrm{~V}$.

effectiveness of the proposed converter. The specifications and circuit parameters of the proposed converter are: $V_{i n}=480-580 \mathrm{~V}, V_{o}=24 \mathrm{~V}, P_{o}=1 \mathrm{~kW}, f_{s}=100 \mathrm{kHz}, C_{o}=6600 \mu \mathrm{F}$, $C_{l}=C_{2=} C_{f}=0.47 \mu \mathrm{F}, \quad C_{i n I}=C_{i n 2}=0.68 \mu \mathrm{F}, \quad T_{l}-T_{4}: n_{p} / n_{s}=36 \mathrm{~T} / 8 \mathrm{~T}$, $L_{m l}-L_{m 4}: 620 \mu \mathrm{H}, \quad L_{r l}=L_{r 2}=20 \mu \mathrm{H}, \quad D_{I}-D_{4}:$ FST3160, $S_{1}-S_{4}$ :IRFP460 and $D_{a}-D_{b}: 30 \mathrm{ETH} 06$. The lagging switches $S_{2}$ and $S_{3}$ are designed to have ZVS turn-on at least from $20 \%$ to $100 \%$ load. Fig. 4 gives the measured waveforms of the gate voltages of $S_{1}-S_{4}$, the primary side voltages $v_{p 1}$ and $v_{p 2}$ and the primary side currents at full load and the different input voltages. Three voltage levels are generated on $v_{p 1}$ and $v_{p 2}$. The primary side voltages $v_{p 1}$ and $v_{p 2}$ are phase-shifted by one-half of switching cycle (complementary each other). If $S_{I}$ and $S_{2}$ are both in the on-state, the primary side current $i_{L r I}$ decreases and $i_{L r 2}$ increases. On the other hand, $i_{L r 1}$ increases and $i_{L r 2}$ decreases if $S_{1}$ and $S_{2}$ are both in the off-state. It is also clear that the phase shift between $S_{I}$ and $S_{2}$ at $V_{i n}=580 \mathrm{~V}$ is greater than the phase shift at $V_{i n}=480 \mathrm{~V}$. Therefore, the primary side voltages $v_{p 1}$ and $v_{p 2}$ at $V_{i n}=580 \mathrm{~V}$ have less duty cycle to transfer power form input voltage to output load. Fig. 5 gives the measured results of the gate voltage, drain voltage and switch current of the leading switch $S_{1}$ and the lagging switch $S_{2}$ at $20 \%$ load for low and high input voltages. It is clear in Fig. 5 that the leading and lagging switches $S_{1}$ and $S_{2}$

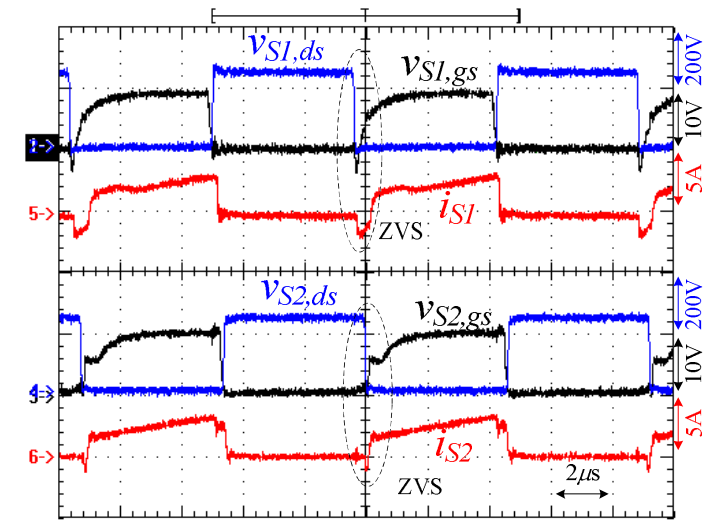

(a)

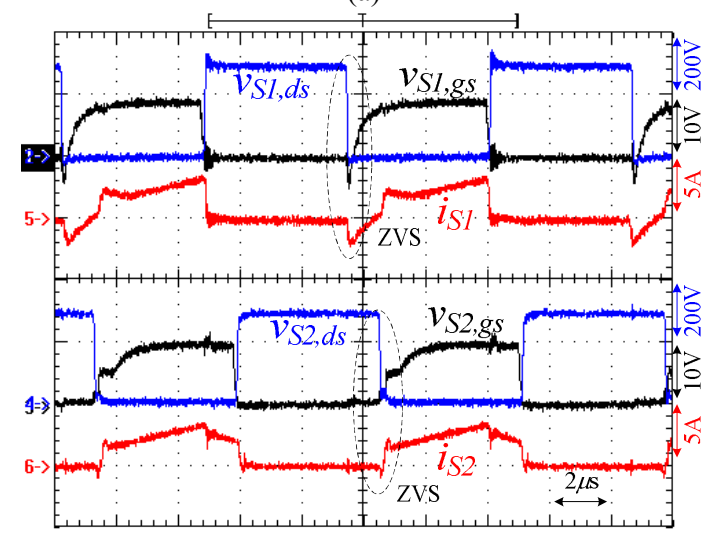

(b)

Fig. 6. Measured results of gate voltage, drain voltage and switch current of $S_{I}$ and $S_{2}$ at $50 \%$ load and (a) $V_{i n}=480 \mathrm{~V}$ (b) $V_{i n}=580 \mathrm{~V}$.

achieve ZVS turn-on at 20\% for low and high input voltages. Similarly, Figs. 6 and 7 give the measured results of the gate voltage, drain voltage and switch current of $S_{1}$ and $S_{2}$ at $50 \%$ and $100 \%$ load, respectively, for both low and high input voltages. The leading and lagging switches are also turned on at ZVS at $50 \%$ and $100 \%$ loads shown in Figs. 6 and 7. The voltage stress of both switches $S_{1}$ and $S_{2}$ is equal to $V_{i n} / 2$. Since the operation behaviors of $S_{3}$ and $S_{4}$ are identical with respective to $S_{2}$ and $S_{1}$, it is clear that $S_{3}$ and $S_{4}$ realize ZVS turn-on from $20 \%$ load to $100 \%$ load. Fig. 8 gives the experimental waveforms of the DC blocking voltages $v_{C l}$ and $v_{C 2}$ and the flying capacitor voltage $v_{C f}$ at full load for both low and high input voltages. The average voltages of $C_{1}, C_{2}$ and $C_{f}$ are equal to $V_{i n} / 2$. Fig. 9 shows the experimental waveforms of the gate voltage $v_{S I, g s}$ and the secondary side diode currents at full load for both low and high input voltages. If switches $S_{1}$ and $S_{2}$ are in the on-state (or off-state), $D_{2}$ and $D_{3}$ (or $D_{1}$ and $D_{4}$ ) are conducting. The output currents $i_{D 1}+i_{D 2}$ and $i_{D 3}+i_{D 4}$ of two three-level PWM circuits are balanced to supply one-half of load current. Fig. 10 shows the measured efficiencies of the proposed converter from $10 \%$ load to full load at different input voltages. 


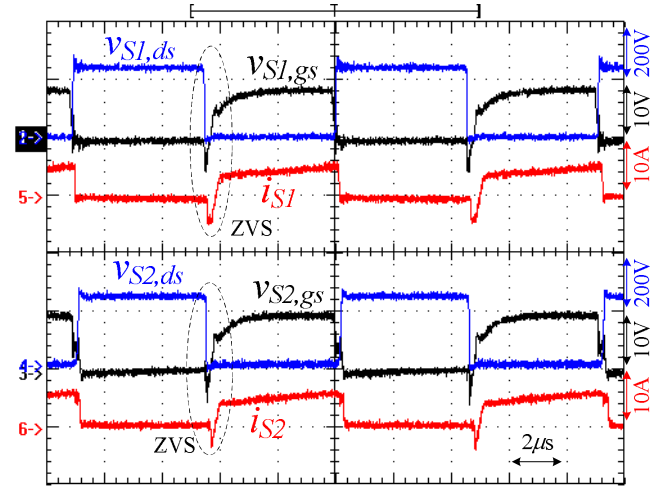

(a)

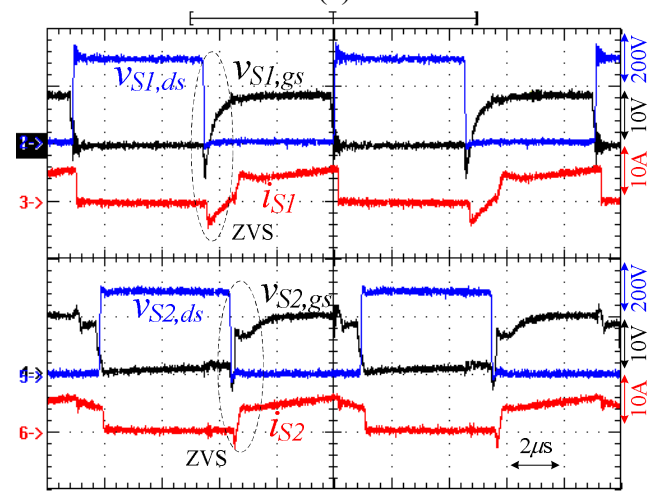

(b)

Fig. 7. Measured waveforms of the gate voltage, drain voltage and switch current of switches $S_{I}$ and $S_{2}$ at $100 \%$ load and (a) $V_{i n}=480 \mathrm{~V}$ (b) $V_{i n}=580 \mathrm{~V}$.

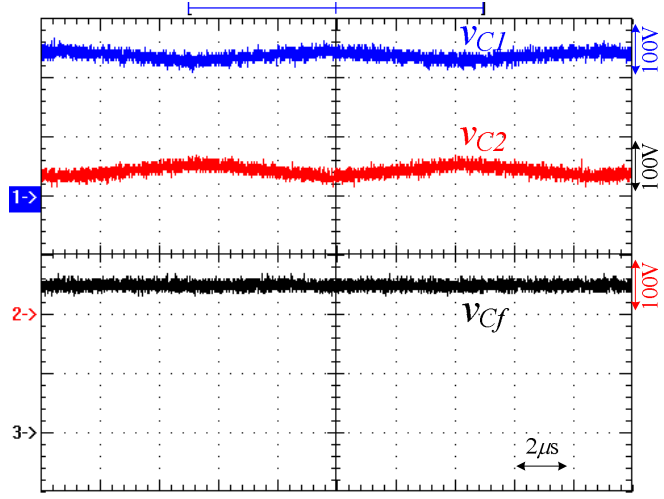

(a)

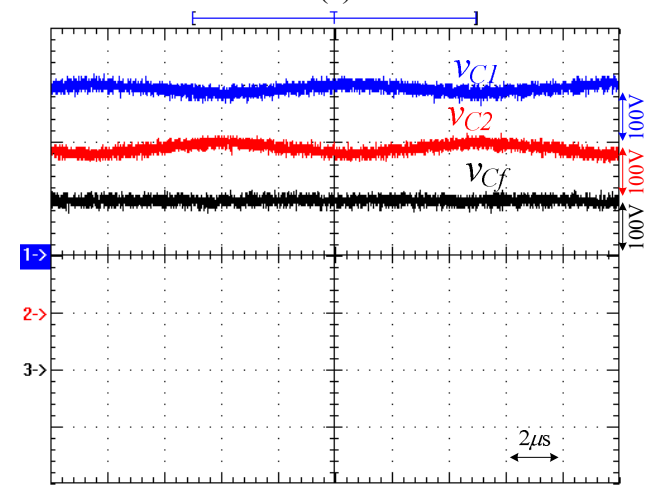

(b)

Fig. 8. Measured waveforms of the DC blocking voltages $v_{C l}$ and $v_{C 2}$ and the flying capacitor voltage $v_{C f}$ at full load and (a) $V_{i n}=480 \mathrm{~V} \mathrm{(b)} V_{\text {in }}=580 \mathrm{~V}$.

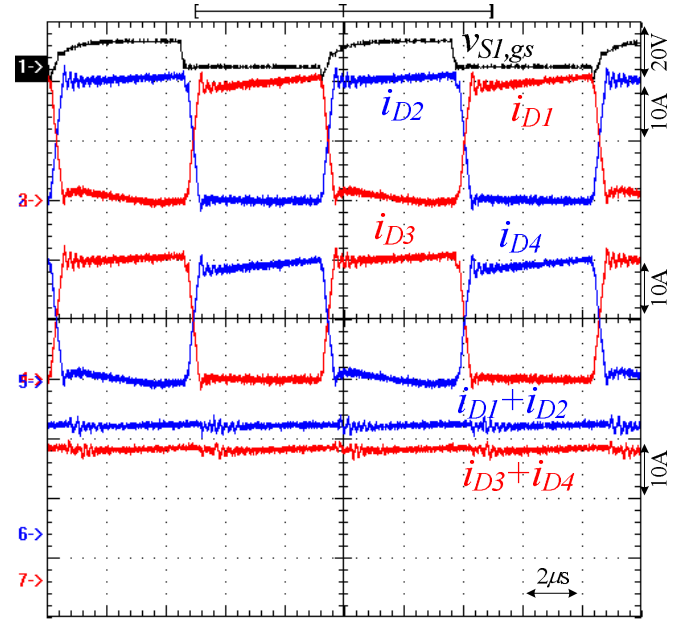

(a)

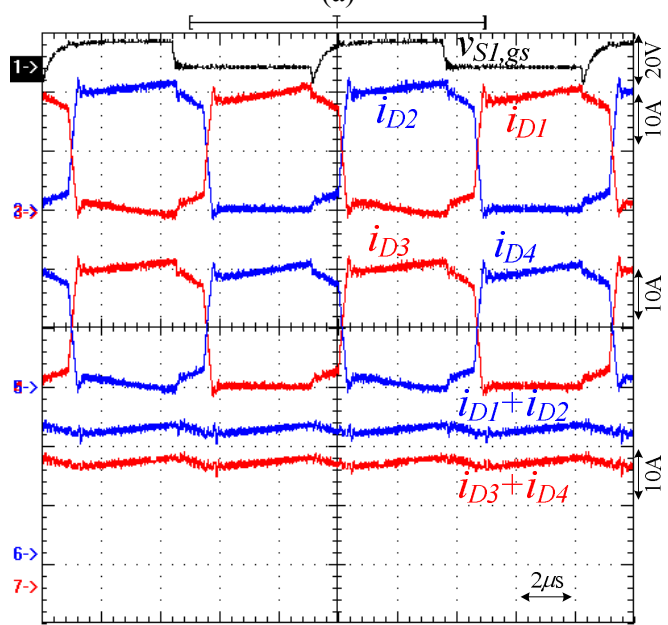

(b)

Fig. 9. Measured waveforms of the rectifier diode currents at full load and (a) $V_{i n}=480 \mathrm{~V}$ (b) $V_{i n}=580 \mathrm{~V}$.

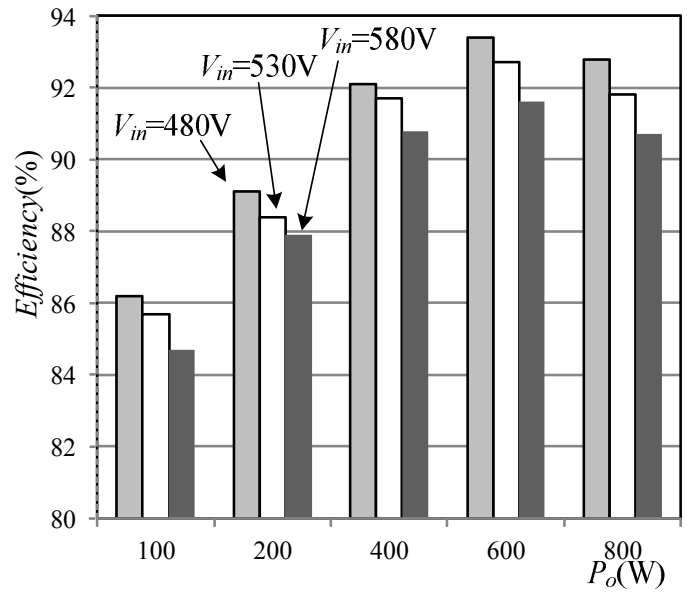

Fig. 10. Measured circuit efficiencies of the proposed converter from $10 \%$ load to $100 \%$ load at different input voltages.

\section{CONCLUSION}

A soft switching DC/DC converter with two three-level PWM circuits with the sane power switches and two series-connected transformers is presented to achieve the 
functions of 1) ZVS turn-on for both the leading and lagging switches from $25 \%$ to $100 \%$ load, 2) low voltage stress of MOSFETs with $v_{\text {stress }}=V_{\text {in }} / 2$ using three-level PWM scheme, 3) no output filter inductors using two series-connected transformers, and 4) low current stress of transformer windings, output inductors and rectifier diodes using two center-tapped circuit topologies. Phase-shift PWM is adopted to generate four PWM signals and to regulate the output voltage. The energy stored in the resonant inductance and magnetizing inductance is used to achieve ZVS turn-on of the leading switches. However, only the energy stored in the resonant inductance is used to achieve ZVS turn-on of the lagging switches. The system analysis, operation mode and design considerations of the proposed converter are discussed in detail. Finally, experiments with $1 \mathrm{~kW}$ prototype are provided to verify the theoretical analysis and demonstrate the effectiveness of the proposed converter.

\section{ACKNOWLEDGMENT}

This paper is supported by the National Science Council of Taiwan under Grant NSC 101-2221-E-224-071 and NSC 102-2221-E-224. The author also thanks Mr. Jhen-Yang Pan for his help to test the results.

\section{REFERENCES}

[1] H. Akagi and R. Kitada, "Control and Design of a Modular Multilevel Cascade BTB System Using Bidirectional Isolated DC/DC Converters," IEEE Trans. Power Electron., Vol. 26, No. 9, pp. 2457-2464, Sep. 2011.

[2] J. Rodriguez, J.-S. Lai, and F. Z. Peng, "Multilevel inverters: a survey of topologies, controls, and applications," IEEE Trans. Ind. Electron., Vol. 49, No. 4, pp. 724-738, Aug. 2002.

[3] M. Malinowski, K. Gopakumar, J. Rodriguez, and M. A. Pérez, "A survey on cascaded multilevel inverters," IEEE Trans. Ind. Electron., Vol. 57, No. 7, pp. 2197-2206, Jul. 2010.

[4] B. R. Lin and C. L. Huang, "Analysis and implementation of a novel soft-switching pulse-width modulation converter," IET Proc.-Power Electronics, Vol. 2, No. 1, pp. 90-101, 2009.

[5] S. S. Lee, S. W. Choi, and G. W. Moon, "High-efficiency active-clamp forward converter with transient current build-up (TCB) ZVS technique," IEEE Trans. Ind. Electron. Vol. 54, No. 1, pp. 310-318, Feb. 2007.

[6] Q. M. Li and F. C. Lee, "Design consideration of the active-clamp forward converter with current mode control during large-signal transient," IEEE Trans. Power Electron., Vol. 18, No. 4, pp. 958-965, Jul. 2003

[7] B. Choi, W. Lim, S. Bang, and S. Choi, "Small-signal analysis and control design of asymmetrical half-bridge DC-DC converters," IEEE Trans. Ind. Electron., Vol. 53, No. 2, pp. 511-520, Apr. 2006.

[8] K. H. Yi and G. W. Moon, "Novel two-phase interleaved LLC series-resonant converter using a phase of the resonant capacitor," IEEE Trans. Ind. Electron., Vol. 56, No. 5, pp. 1815-1819, May 2009.

[9] D. Fu, Y. Liu, F. C. Lee, and M. Xu, "A novel driving scheme for synchronous rectifiers in LLC resonant converters," IEEE Trans. Power Electron., Vol. 24, No. 5, pp. 1321-1329, May 2009.

[10] J. Yungtack, M. M. Jovanovic, and Y. M. Chang, "A new ZVS-PWM full-bridge converter," IEEE Trans. Power Electron., Vol. 18, No. 5, pp. 1122-1129, Sep. 2003.

[11] Y, Jiang, Z. Chen, and J. Pan, "Zero-voltage switching phase shift full-bridge step-up converter with integrated magnetic structure," IET Proc.-Power Electron., Vol. 3, No. 5, pp. 732-739, 2010.

[12] J. P. Rodrigues, S. A. Mussa, I. Barbi, and A. J. Perin, "Three-level zero-voltage switching pulse-width modulation DC-DC boost converter with active clamping," IET Proc.Power Electron., Vol. 3, No. 3, pp. 345-354, 2010.

[13] X. Ruan, D. Xu, L. Zhou, B. Li, and Q. Chen, "Zero-voltage-switching PWM three-level converter with two clamping diodes," IEEE Trans. Ind. Electron., Vol. 49, No. 4, pp. 790-799, Aug. 2002.

[14] J. R. Pinheiro and I. Barbi, "The three-level ZVS-PWM DC-to-DC converter," IEEE Trans. Power Electron., Vol. 8, No. 4, pp. 486-492, Oct. 1993.

[15] F. Canales, P. Barbosa, and F. C. Lee, "A zero-voltage and zero-current switching three-level DC/DC converter," IEEE Trans. Power Electron., Vol. 17, No. 6, pp. 898-904, Nov. 2002.

[16] W. Chen and X. Ruan, "Zero-voltage-switching PWM hybrid full-bridge three-level converter with secondary-voltage clamping scheme," IEEE Trans. Ind. Electron., Vol. 55, No. 2, pp. 644-654, Feb. 2008

[17] Y. Kang, B. Choi, and W. Lim, "Analysis and design of a forward-flyback converter employing two transformers," in proc. IEEE PESC, 2001, pp. 357-362.

[18] J. H. Mulkern, C. P. Henze, and D. S. Lo, "A high-reliablity, low-cost, interleaved bridge converter," IEEE Trans. Electron. Devices, Vol. 38, No. 2, pp. 777-783, Apr. 1991.

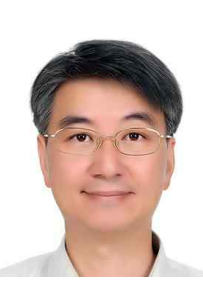

Bor-Ren Lin (S'91-M'93-SM'02) received the B.S.E.E. degree in electronic engineering from the National Taiwan University of Science and Technology, Taipei, Taiwan, in 1988, and the M.S. and Ph.D. degrees in electrical engineering from the University of Missouri-Columbia, USA, in 1990 and 1993, respectively. From 1991 to 1993 , he was a Research Assistant with the Power Electronic Research Center, University of Missouri. Since 1993, he has been with the Department of Electrical Engineering, National Yunlin University of Science and Technology, Douliou, Taiwan, where he is currently a Distinguished Professor. He is an Associate Editor of the Institution of Engineering and Technology Proceedings-Power Electronics and the Journal of Power Electronics. His main research interests include power-factor correction, multilevel converters, active power filters, and soft-switching converters. He has authored more than 200 published technical journal papers in the area of power electronics. Dr. Lin is an Associate Editor of the IEEE Transactions on Industrial Electronics. He was the recipient of the Research Excellence Awards in 2004, 2005, 2007 and 2011 from the Engineering College and the National Yunlin University of Science and Technology. He received the Best Paper Awards from the 2007 and 2011 IEEE Conference on Industrial Electronics and Applications, Taiwan Power Electronics 2007 Conference, and the IEEE-Power Electronics and Drive Systems 2009 Conference. 